\title{
Oxidative Carbonylation of Aromatic Amines with CO Catalyzed by 1,3-Dialkylimidazole-2-selenone in Ionic Liquids
}

\author{
Fengshou Tian, ${ }^{1}$ Yahong Chen, ${ }^{1}$ Xiaofang Wang, ${ }^{2}$ Peng Li, ${ }^{2}$ and Shiwei $\mathrm{Lu}^{2}$ \\ ${ }^{1}$ Department of Chemistry, Zhoukou Normal University, Zhoukou, Henan 466001, China \\ ${ }^{2}$ Dalian Institute of Chemical Physics, Chinese Academy of Sciences, 457 Zhongshan Road, Dalian, Liaoning 116023, China \\ Correspondence should be addressed to Fengshou Tian; fengshoutian@163.com
}

Received 9 February 2015; Revised 24 March 2015; Accepted 27 March 2015

Academic Editor: Andrea Penoni

Copyright (c) 2015 Fengshou Tian et al. This is an open access article distributed under the Creative Commons Attribution License, which permits unrestricted use, distribution, and reproduction in any medium, provided the original work is properly cited.

1,3-Dialkylimidazole-2-selenone as a novel substituted selenium heterocyclic catalyst was used to catalyze oxidative carbonylation of aromatic amines with carbon monoxide in the presence of air to symmetrical ureas in up to $97 \%$ yield in ionic liquids.

\section{Introduction}

In recent years, attention has been paid to a very promising nonphosgene process for the synthesis of various ureas, namely, the reductive carbonylation of nitrocompounds or the oxidative carbonylation of aromatic amines catalyzed by noble metals, including rhodium, ruthenium, and palladium [1-7]. However, oxidative carbonylation of amines or reductive carbonylation of nitrocompounds by selenium catalysts instead of noble metals has been reported to give symmetrical ureas [8-10]. Though these reactions possess these advantages such as the easily available catalyst and phase-transfer catalyst properties [11, 12], selenium-catalyzed carbonylation reactions have a disadvantage that the volatile selenium-containing intermediates $\left(\mathrm{H}_{2} \mathrm{Se}\right)$ generated in the reaction produce unbearable and toxic odour. The use of selenium-containing catalyst is a trend in selenium-catalyzed reaction for safety and green chemistry purposes.

In the course of our ongoing investigations on the selenium-catalyzed carbonylation reaction, we have discovered that symmetrical ureas could be obtained from the carbonylation of nitrobenzene or substituted nitroarene under solvent-free conditions [13] or under atmospheric pressure [14] or in ionic liquids [15].

Recently, we also have reported the synthesis of 1,3-dialkylimidazole-2-selenones using 1,3-dialkylimidazolium salts with selenium in water or in ethanol or acetone $[16,17]$. Keeping this result in mind, we reported 1,3-dialkylimidazole2-selenone catalyzed oxidative carbonylation of aromatic amines with carbon monoxide in the presence of oxygen in ionic liquids (Scheme 1).

\section{Experimental}

Imidazolin-2-selenones were synthesized according to the literature [17]. The organic solvents were all of reagent grade and were used without further purification. Ionic liquids were synthesized according to the literature [18]. Selenium (99.5\%) and carbon monoxide (99\%) and organic amines were all used as purchased. Melting points were determined on a Taike X-4 apparatus (Beijing, China) and are uncorrected. ${ }^{1} \mathrm{H}$ and ${ }^{13} \mathrm{C}$ NMR spectra were obtained on a Bruker DRX 400 spectrometer. Chemical shifts were reported in parts per million relative to tetramethylsilane ( $\delta$ units), with dimethylsulfoxide (DMSO- $\mathrm{d}_{6}$ ) as solvent.

2.1. General Procedure. $5 \mathrm{mmol}$ of aniline, $0.46 \mathrm{mmol}$ of selenium-containing catalyst, and $0.25 \mathrm{~g}[\mathrm{BMIM}] \mathrm{BF}_{4}$ were sealed in a $100 \mathrm{~mL}$ stainless steel autoclave. The reactor was pressurized with $0.2 \mathrm{Mpa}$ oxygen and $1.1 \mathrm{Mpa}$ carbon monoxide and then placed in an oil bath preheated to $90^{\circ} \mathrm{C}$; after $6 \mathrm{~h}$ of the reaction time, the apparatus was degassed, and the 1,3-diaryl urea was separated from [BMIM] $\mathrm{BF}_{4}$ by adding acetone and water to the reaction mixtures. Purification by column chromatography on silica gel or recrystallization gave the urea product. Products were identified by NMR measurements and/or comparison with authentic samples. 


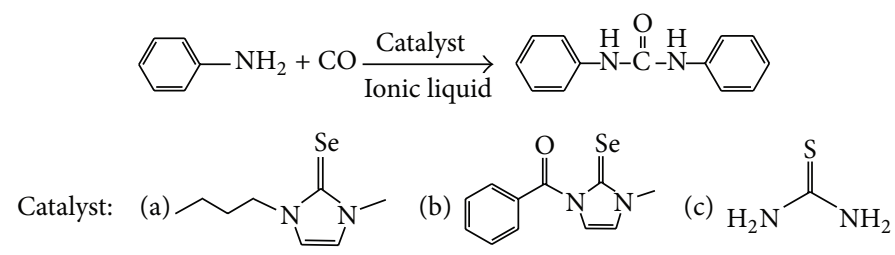

SCHEME 1

TABLE 1: The study of the reaction in different conditions.

\begin{tabular}{|c|c|c|c|c|c|}
\hline Entry $^{a}$ & Catalyst a (mmol) & IL (g) & Base & Temperature $\left({ }^{\circ} \mathrm{C}\right)$ & Yield $(\%)^{\mathrm{f}}$ \\
\hline 1 & 0.46 & 0.25 & - & 90 & 94 \\
\hline $2^{\mathrm{b}}$ & 0.46 & 0.25 & - & 90 & 34 \\
\hline $3^{c}$ & 0.46 & 0.25 & - & 90 & 25 \\
\hline $4^{\mathrm{d}}$ & 0.46 & 0.25 & - & 90 & 5 \\
\hline 5 & 0.46 & 0 & - & 90 & 19 \\
\hline 6 & 0.46 & $0.25^{\mathrm{e}}$ & - & 90 & 19 \\
\hline 7 & 0.46 & 0.25 & $\mathrm{Et}_{3} \mathrm{~N}$ & 90 & $<3$ \\
\hline 8 & 0.46 & 0.25 & $\mathrm{~K}_{2} \mathrm{CO}_{3}$ & 90 & $<5$ \\
\hline 9 & 0.46 & 0.25 & - & 60 & 34 \\
\hline 10 & 0.46 & 0.50 & - & 60 & 57 \\
\hline 11 & 0.46 & 0.25 & HOAc & 90 & 57 \\
\hline
\end{tabular}

${ }^{\mathrm{a}}$ Reaction conditions: aniline $(5.0 \mathrm{mmol}) ; \mathrm{IL}$ is $[\mathrm{BMIM}] \mathrm{BF}_{4}$; Pair $=0.2 \mathrm{Mpa}$, Pair + Pco $=1.3 \mathrm{Mpa} ;{ }^{\mathrm{b}}$ catalyst is selenium; ${ }^{\mathrm{c}}$ catalyst is $\mathbf{b} ;{ }^{\mathrm{d}}$ catalyst is $\mathbf{c} ;{ }^{\mathrm{e}} \mathrm{IL}$ is $[\mathrm{BMIM}] \mathrm{Cl} ;{ }^{\mathrm{f}}$ isolated yields.

\section{Results and Discussion}

Aniline was treated with 1-butyl-3-methyl-imidazole-2selenone and carbon monoxide and air in the presence of [BMIM] $\mathrm{BF}_{4}$ at $90^{\circ} \mathrm{C}$ for $6 \mathrm{~h}$. Oxidative carbonylation of aniline efficiently led to N,N-diphenylurea in $94 \%$ yield (Table 1, entry 1). We found that the reaction catalyzed by different catalysts exhibited different yields of urea (Table 1, entries 1-4) and $\mathbf{a}$ is the best catalyst in the reaction. The reaction proceeded very slowly in the absence of ionic liquid (Table 1, entry 5) and the efficiency of use of [BMIM]BF is better than that of use of [BMIM]Cl (Table 1, entries 1 and 6). It is well known that the base plays an important role during selenium-catalyzed reaction $[23,24]$. In the reaction, both $\mathrm{Et}_{3} \mathrm{~N}$ and $\mathrm{K}_{2} \mathrm{CO}_{3}$ increase the reaction efficiency but no reaction occurs (Table 1, entries 7-8). The reaction occurred without use of a base (Table 1 ). The yield of N,N-diphenylurea increased when adding amount of the $[\mathrm{BMIM}] \mathrm{BF}_{4}$ or raising the reaction temperature (Table 1 , entries 1, 8-9). When HOAc was used in the reaction, the yield of N,N-diphenylurea is up to $57 \%$; the reason may be decomposition of containing selenium catalyst under acidic condition (Table 1, entry 11).

To test the reusability of the catalyst and the ionic liquid, the oxidative carbonylation of aniline was performed using 1-butyl-3-methyl-imidazole-2-selenone as catalyst in the presence of $\mathrm{CO}$ and air (Pair $=0.2 \mathrm{Mpa}$, Pair + Pco $=$ $1.3 \mathrm{Mpa}$ ) in ionic liquid at $90^{\circ} \mathrm{C}$ for $6 \mathrm{~h}$ (Table 2). After the reaction was complete, the 1,3-diaryl urea was separated from $[\mathrm{BMIM}] \mathrm{BF}_{4}$ by adding acetone and water to the reaction mixture; the resultant liquor containing the catalyst and ionic
TABLE 2: Reusability of the catalysts in the reaction.

\begin{tabular}{|c|c|c|}
\hline Entry $^{a}$ & Cycle & Yield $^{\mathrm{b}}$ \\
\hline 1 & 0 & 94 \\
\hline 2 & 1 & 96 \\
\hline 3 & 2 & 99 \\
\hline 4 & 3 & 92 \\
\hline
\end{tabular}

liquid was reused with a fresh charge of aniline. Catalyst exhibited better activity than it did in the original runs. The yield of the symmetrical urea increased upon recycling the catalyst, suggesting that unchanged substrates might have participated in the subsequent reaction (Table 2).

In a fashion similar to the synthesis of symmetrical ureas, the oxidative carbonylation of aniline was investigated, and the results are summarized in Table 3 . It is noteworthy that all aromatic amines could undergo the same type of reactions under the conditions as stated in Table 3 (entries 1-6). Increasing steric hindrance on the phenyl rings of the substrate obviously dropped to the product yield (17\%) (Table 3, entry 3). 1-Naphthylamine and 2-aminopyridine gave the corresponding ureas in $41 \%$ and $40 \%$ (Table 3, entries 5-6). When aniline and 4-methylaniline were used as the substrate, the yields of the intended products were obtained in $94 \%$ and $97 \%$ (Table 3, entries 1 and 2), but using 4acetylaniline as the substrate, the product yield decreased in $7 \%$ rapidly (Table 3 , entry 4 ). 
TABLE 3: The synthesis of symmetrical ureas from organic amines.

Eield
$(\%)^{\circ}$

${ }^{\mathrm{a}}$ Reaction conditions: catalyst a $(0.10 \mathrm{~g}),\left[\mathrm{BMIM}_{\mathrm{B}} \mathrm{BF}_{4}(0.25 \mathrm{~g})\right.$, amine $(5.0 \mathrm{mmol})$; Pair + Pco $=1.3 \mathrm{Mpa}$; reaction time $=6 \mathrm{~h} ;{ }^{\mathrm{b}} 65-75 \%$ aqueous solution; ${ }^{\mathrm{c}}$ isolated yields.

Aliphatic amines exhibited a higher activity than aromatic amines in a lower temperature $\left(60^{\circ} \mathrm{C}\right)$. Without use of the ionic liquid, the reaction occurs satisfactorily (Table 3, entries 8-9). Complete conversions were achieved for aliphatic amines over a period of $6 \mathrm{~h}$, and the symmetrical ureas were obtained in moderate to good yields (52-98\%) after workup (Table 3, entries 7-12). When dimethylamine aqueous solution $(65-75 \%)$ was used as the substrate, the product yield was $52 \%$ (Table 3 , entry 9), but the reaction did not proceed in the presence of piperidine (Table 3 , entry 10). Long-chain aliphatic amines and cyclohexanemethylamine afforded the symmetrical ureas in $91-98 \%$ yields (Table 3, entries 11-13).

\section{Conclusion}

In conclusion, we have found a synthetic method for the symmetrical ureas from amines and selenium-containing catalyst and carbon monoxide through oxidative carbonylation reaction. The odour that exists in elemental seleniumcatalyzed carbonylation reactions was not present in this catalytic system. The in situ generated inorganic selenium compounds (such as $\mathrm{H}_{2} \mathrm{Se}$ ) that are mainly responsible for the unbearable and toxic odour in selenium-catalyzed carbonylation reactions can be avoided because of seleniumcontaining catalyst (the chemical loading of selenium). Although the mechanism for formation of symmetrical ureas using selenium-containing catalyst has not been clarified, the reason may be the result of selenium-containing catalysts directly involved in the reaction and avoiding the generation of toxic gases. Further studies regarding the mechanism are underway.

\section{Data of Some Products}

$\mathrm{N}, \mathrm{N}^{\prime}$-Diphenylurea: ${ }^{1} \mathrm{H}$ NMR (DMSO- $\mathrm{d}_{6}, 400 \mathrm{MHz}$ ): $8.68(\mathrm{~s}, 2 \mathrm{H}), 7.47(\mathrm{~m}, 4 \mathrm{H}), 7.29(\mathrm{~m}, 4 \mathrm{H}), 6.98(\mathrm{~m}, 2 \mathrm{H})$; 
${ }^{13} \mathrm{C}$ NMR (DMSO-d 6 , $\left.400 \mathrm{MHz}\right): \delta=152.5,139.7$, 128.8, 121.9, 118.2.

$\mathrm{N}, \mathrm{N}^{\prime}$-Bis(4-methylphenyl)urea: ${ }^{1} \mathrm{H}$ NMR (DMSO$\left.\mathrm{d}_{6}, 400 \mathrm{MHz}\right): 8.50$ (s, $\left.2 \mathrm{H}\right), 7.33$ (d, $\left.4 \mathrm{H}\right), 7.07$ (d, $\left.4 \mathrm{H}\right)$, $2.24(\mathrm{~s}, 6 \mathrm{H}) ;{ }^{13} \mathrm{C}$ NMR (DMSO-d $\left.{ }_{6}, 400 \mathrm{MHz}\right): \delta=$ 152.6, 137.2, 130.5, 129.2, 118.2, 20.4.

$\mathrm{N}, \mathrm{N}^{\prime}$-Bis(2-methylphenyl)urea: ${ }^{1} \mathrm{H}$ NMR (DMSO$\left.\mathrm{d}_{6}, 400 \mathrm{MHz}\right): 8.24$ (s, 2H), 7.82 (d, 2H), 7.18-7.13 (m, $4 \mathrm{H}), 6.95(\mathrm{~m}, 2 \mathrm{H}), 2.26(\mathrm{~s}, 6 \mathrm{H}) ;{ }^{13} \mathrm{C}$ NMR (DMSO-d ${ }_{6}$, $400 \mathrm{MHz}): \delta=152.9,137.5,130.2,127.7,126.1,122.7$, 121.5, 18.0.

$\mathrm{N}, \mathrm{N}^{\prime}$-Bis(4-methoxyphenyl)urea: ${ }^{1} \mathrm{H}$ NMR (DMSO$\left.\mathrm{d}_{6}, 400 \mathrm{MHz}\right): 9.26(\mathrm{~s}, 2 \mathrm{H}), 8.17$ (d, $\left.4 \mathrm{H}\right), 7.89(\mathrm{~d}, 4 \mathrm{H})$, $2.77(\mathrm{~s}, 6 \mathrm{H}) ;{ }^{13} \mathrm{C}$ NMR (DMSO-d $\left.\mathrm{d}_{6}, 400 \mathrm{MHz}\right): \delta=$ 195.7, 151.5, 143.6, 130.7, 130.1, 129.1, 117.3, 25.7.

N,N'-Dimethylurea: ${ }^{1} \mathrm{H}$ NMR (DMSO- $\mathrm{d}_{6}, 400 \mathrm{MHz}$ ): $5.50(\mathrm{~s}, 2 \mathrm{H}), 3.19(\mathrm{q}, 4 \mathrm{H}), 1.11(\mathrm{t}, 6 \mathrm{H}) ;{ }^{13} \mathrm{C} \mathrm{NMR}$ (DMSO-d $\left.{ }_{6}, 400 \mathrm{MHz}\right): \delta=158.8,34.5,15.1$.

N,N'-Diisopropylurea: ${ }^{1} \mathrm{H} \quad$ NMR $\quad$ (DMSO- $\mathrm{d}_{6}$, $400 \mathrm{MHz}): 5.36$ (d, $2 \mathrm{H}), 3.68(\mathrm{~m}, 2 \mathrm{H}), 1.02(\mathrm{~d}, 12 \mathrm{H})$; ${ }^{13} \mathrm{C}$ NMR (DMSO-d $\mathrm{d}_{6}, 400 \mathrm{MHz}$ ): $\delta=156.6,40.38$, 22.8 .

\section{Conflict of Interests}

The authors would like to declare that they do not have any commercial or associative interests that represent a conflict of interests in connection with the submitted paper.

\section{Acknowledgments}

The authors are grateful for financial support from the Natural Science Foundation of Henan Province (Project nos. 142102310365 and 142300410417) and the Natural Science Foundation of Education Department of Henan Province (nos. 14A150015 and 15A150087).

\section{References}

[1] F. Ragaini, A. Ghitti, and S. Cenini, "Mechanistic study of the $\mathrm{Ru}_{3}(\mathrm{CO})_{12} /$ Tetraalkylammonium chloride catalyzed carbonylation reactions of nitroarenes to carbamates and ureas: a completely revised picture," Organometallics, vol. 18, no. 24, pp. 4925-4933, 1999.

[2] I. Chiarotto and M. Feroci, "Selective and environmentally friendly methodologies based on the use of electrochemistry for fine chemical preparation: an efficient synthesis of $\mathrm{N}, \mathrm{N}^{\prime}$ disubstituted ureas," Journal of Organic Chemistry, vol. 68, no. 18, pp. 7137-7139, 2003.

[3] Z. Li, Z. Y. Wang, W. Zhu, Y. L. Xing, and Y. L. Zhao, " $\mathrm{CeCl}_{3} \cdot 7 \mathrm{H}_{2} \mathrm{O}$-KI-cataylzed, environmentally friendly synthesis of $\mathrm{N}, \mathrm{N}^{\prime}$-disubstituted ureas in water under microwave irradiation," Synthetic Communications, vol. 35, no. 17, pp. 2325-2331, 2005.

[4] T. Kondo, "Novel ruthenium-complex-catalyzed synthesis of ureas from formamides and amines," Organometallics, vol. 16, no. 12 , pp. 2562-2570, 1997.
[5] S. M. Islam, D. Mal, B. K. Palit, and C. R. Saha, "Reductive carbonylation of nitroaromatics using $\mathrm{RhA}(\mathrm{CO})_{2}$," Journal of Molecular Catalysis A: Chemical, vol. 142, no. 2, pp. 169-181, 1999.

[6] P. Wehman, L. Borst, P. C. J. Kamer, and P. W. N. M. van Leeuwen, "Influence of an aromatic carboxylic acid as cocatalyst in the palladium- catalysed reductive carbonylation of aromatic nitro compounds," Journal of Molecular Catalysis A: Chemical, vol. 112, no. 1, pp. 23-36, 1996.

[7] A. M. Tafesh and J. Weiguny, "A review of the selective catalytic reduction of aromatic nitro compounds into aromatic amines, isocyanates, carbamates, and ureas using CO," Chemical Reviews, vol. 96, no. 6, pp. 2035-2052, 1996.

[8] H. S. Kim, Y. J. Kim, H. J. Lee, M. J. Chung, and S. D. Lee, "Preparing N, N'-disubstituted urea using selenium-based catalyst," Patent US 6127575, 1999.

[9] X. Zhang, D. Li, X. Ma, Y. Wang, and G. Zhang, "Synthesis of unsymmetrical 2-pyridyl ureas via selenium-catalyzed oxidative carbonylation of 2-aminopyridine with aromatic amines," Synthesis, vol. 45, no. 10, Article ID SS-2013-F0083-OP, pp. 13571363, 2013.

[10] N. Sonoda, T. Yasuhara, K. Kondo, T. Ikeda, and S. Tsumi, "A new synthesis of ureas. The reaction of ammonia or aliphatic amines with carbon monoxide in the presence of selenium," Journal of the American Chemical Society, vol. 93, no. 23, p. 6344, 1971.

[11] Y. Yang and S. W. Lu, "Selenium-catalyzed reductive carbonylation of nitrobenzene with amines as coreagents to give unsymmetric phenylureas," Tetrahedron Letters, vol. 40, no. 26, pp. 4845-4846, 1999.

[12] J. Mei, Y. Yang, Y. Xue, and S. Lu, "Selective formation of unsymmetric ureas by selenium-catalyzed oxidative-reductive carbonylation with CO," Journal of Molecular Catalysis A: Chemical, vol. 191, no. 1, pp. 135-139, 2003.

[13] X. Wang, P. Li, X. Yuan, and S. Lu, "Selenium-catalyzed carbonylation of nitroarenes to symmetrical 1,3-diarylureas under solvent-free conditions," Journal of Molecular Catalysis A: Chemical, vol. 253, no. 1-2, pp. 261-264, 2006.

[14] X. F. Wang, S. W. Lu, and Z. K. Yu, "Highly efficient route to diselenides from the reactions of imines and selenium in the presence of carbon monoxide and water," Advanced Synthesis \& Catalysis, vol. 346, pp. 929-932, 2004.

[15] X. F. Wang, P. Li, X. H. Yuan, and S. W. Lu, "Synthesis of symmetrical 1,3-diarylureas by sulfur-catalyzed carbonylation in ionic liquids," Journal of Molecular Catalysis A: Chemical, vol. 255, no. 1-2, pp. 25-27, 2006.

[16] F. S. Tian, Y. H. Chen, L. Wu, P. Li, and S. W. Lu, "An efficient synthesis of 1,3-dialkylimidazole-2-selenones," Journal of Chemical Research, vol. 38, no. 6, pp. 375-377, 2014.

[17] F. Tian, Y. Chen, P. Li, and S. Lu, "A novel method for synthesis of 1, 3-Dialkylimidazole-2-selenones in water," Phosphorus, Sulfur, and Silicon and the Related Elements, vol. 189, no. 9, pp. 13911395, 2014.

[18] J. S. Wilkes, J. A. Levisky, R. A. Wilson, and C. L. Hussey, "Dialkylimidazolium chloroaluminate melts: a new class of room-temperature ionic liquids for electrochemistry, spectroscopy and synthesis," Inorganic Chemistry, vol. 21, no. 3, pp. 1263-1264, 1982.

[19] M. A. Pasha and M. B. M. Reddy, "Efficient method of synthesis of N,N /-disubstituted ureas/thioureas by a zinc chloride catalyzed thermal reaction," Synthetic Communications, vol. 39, no. 16, pp. 2928-2934, 2009. 
[20] T. L. Kurth and F. D. Lewis, "Ground-State Conformational Equilibrium and Photochemical Behavior of Syn and Anti N,N'-Dimethyl-N, N' -di-1-naphthylurea Protophanes," Journal of the American Chemical Society, vol. 125, no. 45, pp. 1376013767, 2003.

[21] C. H. Chien, M. K. Leung, J. K. Su, G. H. Li, Y. H. Liu, and Y. Wang, "Substituent effects on pyrid-2-yl ureas toward intramolecular hydrogen bonding and cytosine complexation," Journal of Organic Chemistry, vol. 69, no. 6, pp. 1866-1871, 2004.

[22] M. S. Khajavi, M. G. Dakamin, H. Hazarkhani, M. Hajihadi, and F. Nikpour, "An efficient one-pot procedure for preparation of symmetrical $\mathrm{N}, \mathrm{N}^{\prime}$-disubstituted ureas from aromatic and aliphatic amines and urea under microwave irradiation," Iranian Journal of Chemistry and Chemical Engineering, vol. 19, no. 1, pp. 24-28, 2000.

[23] X. Liu and S. Lu, "Selective formation of aromatic amines by selenium-catalyzed reduction of aromatic nitro compounds with $\mathrm{CO} / \mathrm{H}_{2} \mathrm{O}$ under atmospheric pressure," Journal of Molecular Catalysis A: Chemical, vol. 212, no. 1-2, pp. 127-130, 2004.

[24] X. F. Wang, G. Ling, Y. Xue, and S. W. Lu, "Selenium-catalyzed reductive carbonylation of 2-nitrophenols to 2-benzoxazones," European Journal of Organic Chemistry, vol. 36, no. 34, pp. 16751679, 2005. 

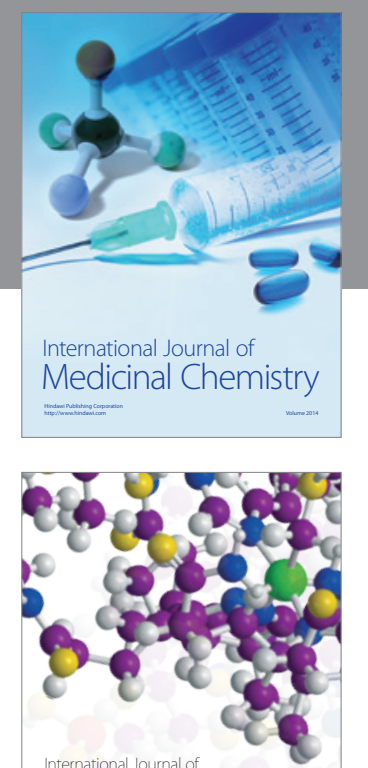

\section{Carbohydrate} Chemistry

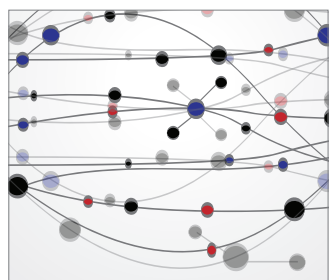

The Scientific World Journal
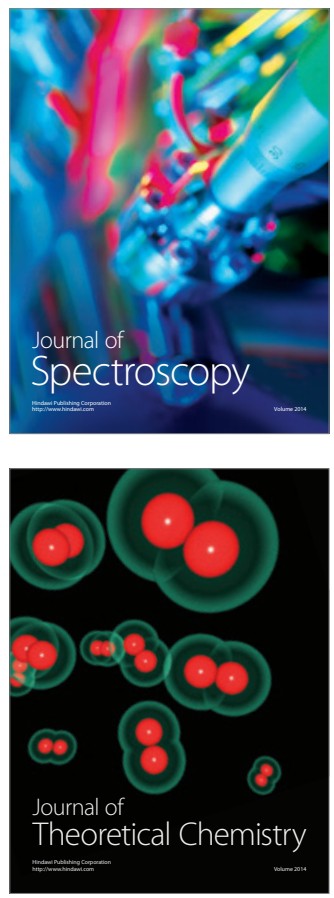
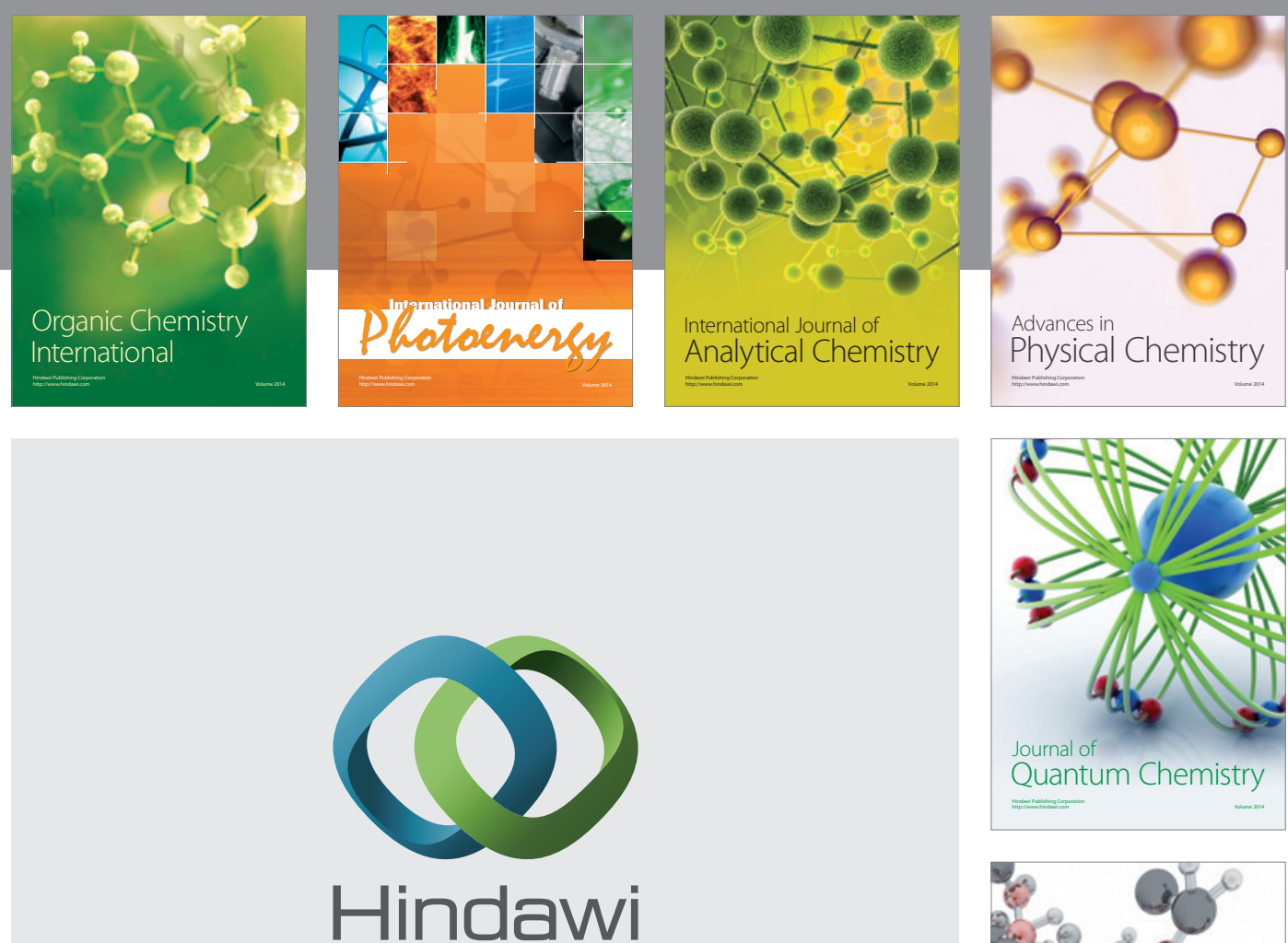

Submit your manuscripts at

http://www.hindawi.com

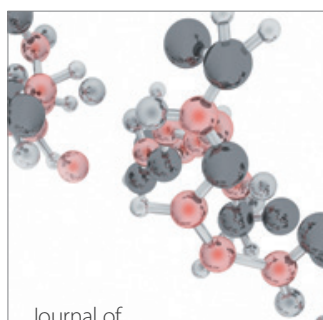

Analytical Methods

in Chemistry

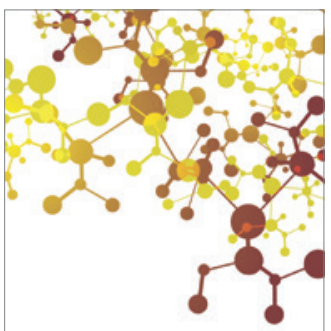

Journal of

Applied Chemistry

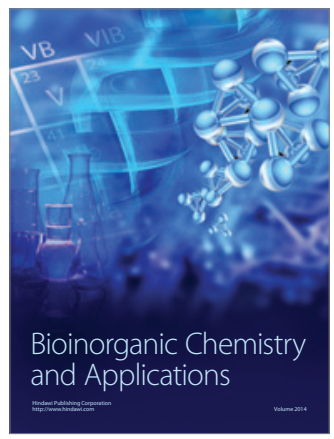

Inorganic Chemistry
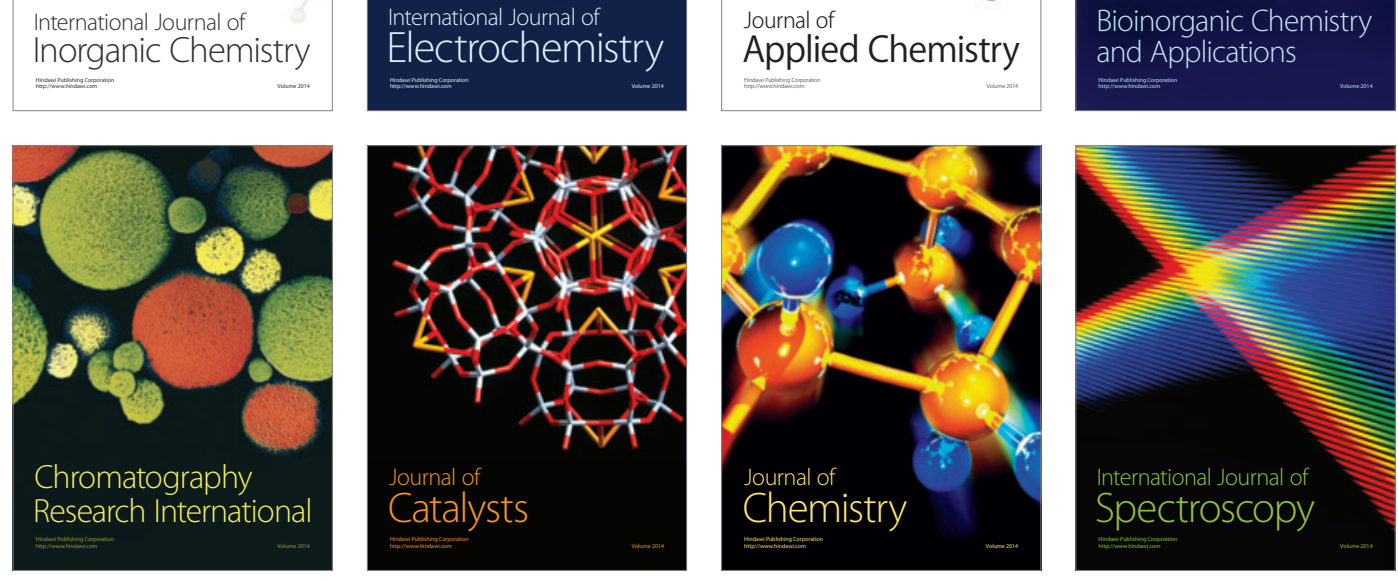